\title{
Emotional intelligence:The context for successful nursing leadership: a literature review
}

\begin{abstract}
Background: A leader is the stronghold of any organization and leadership styles have evolved and transformed along with mankind. Leadership styles have varied from one-dimensional model to multidimensional models. From static styles practiced in the past to dynamic styles in the current contemporary world. Nursing leaders have mirrored the leadership styles adopted in their tenure of practice. The dynamism in the current worldwide scenario, has favoured the nursing leaders to adopt emotional intelligence in their practice. Emotionally intelligent nursing leadership style has been successfully implemented palliative care, oncology and mental health settings.
\end{abstract}

Methods: A systematic review of literature based on emotional intelligence among nursing leaders, published between 2008 and 2015 from selected databases was done. A total of thirteen articles were included in the review. The selected articles were critically appraised using the Rating System for the Hierarchy of Evidence: Nursing Resources.

Results: The focus in the selected articles were centred around the basic nature of emotional intelligence, its significance in the global health care delivery system and the intricacies in implementing emotionally intelligent leadership by nursing leaders. Three significant themes emerged from the findings of the reviewed studies. Emotional intelligence is a charismatic virtue for Nurse Leaders, emotional intelligence remediates the chronic challenges in nursing practice, and the success of emotional intelligence is in its implementation.

Discussion: Implications to incorporate emotional intelligence into the nursing curriculum, future scope of research in this domain and a need to recruit emotionally intelligent nurse managers have been implied.

Keywords: nursing leaders, emotional intelligence, self-awareness, self-regulation, nursing practice

\author{
Volume 2 Issue 6 - 2017 \\ Joshy Abraham,' Jaimy Scaria² \\ 'Department of Nursing, Sultan Qaboos University, Oman \\ ${ }^{2}$ Clinical Instructor, AFMSS, Oman
}

Correspondence: Joshy Abraham, Department of Nursing, Sultan Qaboos University, Oman, Email joshy@squ.edu.om

Received: March 28, 2017| Published: May 17, 2017
Key message: Emotional intelligence is a dynamic virtue with requires proactive, self-reflective practices and empathizes on behaviours based on experiential knowledge. It serves as a remediation for contemporary health care issues. Nurse leaders equipped with emotional intelligence are strategically placed to manage changes, resolve conflicts and maintain clinical competence standards.

\section{Introduction}

Leadership is the cornerstone for an organizational and has been moulded over the centuries to its current form. In ancient times, any person with a dominant personality was considered the leader, this was the evolution of the autocratic style of leadership. The enormous physical and emotional pressure felt by the subordinates in this leadership style paved the way for the democratic style, which considered the needs and problems of the subordinates, and assigned tasks which could be efficiently and effectively performed by a person. As decades passed by some democratic leaders failed to maintain their standards, and allowed the 'laissez faire' leadership style to permeate. This style was characterized by autonomy and decision making powers to the subordinates, with the leader serving as a 'puppet' dancing to the tunes of the subordinate.

\section{Background}

Over the past few decades, organizations realized that, implementing a single style of leadership was unfruitful and a mixed method which incorporated all the components discussed above was effective. This was called as the transformational leadership style, which yielded higher productivity and satisfaction in organizations. The major disadvantage stemming from this model of leadership was the inability of the leader to decide on which standard of leadership to adapt to in a given situation. This mismatched situation created the environment for the incorporation of emotional intelligence into leadership. Spano-Szekely ${ }^{1}$ has empirically postulated that emotional intelligence is positively correlated with transformational leadership and negatively correlated with 'laissez faire' leadership.

Varied leadership styles have been utilized in nursing. Vesterinen studied the leadership style practiced by Finnish nurse managers and has broadcasted the styles practiced as visionary, coaching, affiliate, democratic and commanding. From the perspective of Rishel, ${ }^{2}$ leadership development in nursing should focus on development of their innate sense of purpose and enrichment of their emotional intelligence.

Emotional intelligence (EI) is the capacity of individuals to recognize their own, and other people's emotions, to discriminate between different feelings and label them appropriately, and to use emotional information to guide thinking and behaviour. It is generally said to include 3 skills:1. Emotional awareness, including the ability to identify your own emotions and those of others; 2 . The 
ability to harness emotions and apply them to tasks like thinking and problems solving; 3 . The ability to manage emotions, including the ability to regulate your own emotions, and the ability to cheer up or calm down another person. Emotional intelligence is connected with positive authorization processes as well as positive administrative effects. Emotionally intelligent nurse leadership characterized by self-awareness and supervisory skills and positive empowerment processes, creating a favorable work environment characterized by flexibility, novelty and transformation. Emotional intelligence cannot be measured a general solution, but it may offer new ways of thinking and being for nurse leaders, as it takes the intelligence of feelings more seriously by frequently reflecting, evaluating and improving leadership and supervisory skills.

Emotional intelligence has been empirically tested to yield convincing results in mental health nursing ${ }^{3}$ and palliative care settings. ${ }^{4}$ The benefits achieved by the employees were an improved overall health, increased work satisfaction, higher spiritual well-being and decreased burn-out. Therefore it is very important to develop emotional intelligence in leadership.

\section{Methods}

\section{Search strategy}

The review included article published from 2008 to 2016. The following electronic databases were searched CINAHL, Medline, SCOPUS, OVID and EBSCO. Key words used included emotional

Table I Rating system for the hierarchy of evidence: nursing resources. intelligence, nurse leaders, nurse managers, self-awareness, reflection, self-regulation and job satisfaction.

\section{Inclusion criteria}

Scholarly articles based on

i. Emotional intelligence in Nursing Practice.

ii. Nursing leaders/managers employing emotional intelligence.

iii. English language.

iv. Quantitative, qualitative and review studies

\section{Exclusion criteria}

Included studies which focused on application of emotional intelligence in other health care professionals.

\section{Critical appraisal}

Quality assessment of the selected studies was done by experts in nursing education and practice; The Methodological quality of the studies chosen was ranked utilizing the rating system for hierarchy of evidence: nursing resources Table 1 . Meta-analysis was not performed due to the variations in tools and methods used. Data Extraction: a total of thirteen journal articles were included in the review. All articles selected for review were entered into a bibliographic software package (Endnote Version 7). Synthesis of data was presented in text and tabular format.

\begin{tabular}{ll}
\hline Level & Definition \\
\hline Level I & $\begin{array}{l}\text { Evidence from a systematic review of all relevant randomized controlled trials (RCT's), or evidence-based clinical } \\
\text { practice guidelines based on systematic reviews of RCT's }\end{array}$ \\
Level II & Evidence obtained from at least one well-designed Randomized Controlled Trial (RCT) \\
Level III & Evidence obtained from well-designed controlled trials without randomization, quasi-experimental \\
Level IV & Evidence from well-designed case-control and cohort studies \\
LevelV & Evidence from systematic reviews of descriptive and qualitative studies \\
LevelVI & Evidence from a single descriptive or qualitative study \\
Level VII & Evidence from the opinion of authorities and/or reports of expert committees \\
\hline
\end{tabular}

\section{Results}

Table 2 summarizes the studies reviewed for the current study. The studies selected were globally diverse. Majority (five) of the articles

Table 2 Essentials on the literature review of emotional intelligence were experiential opinions or reports. Four of them belonged to Level $\mathrm{IV}$, three of the qualified articles were either a single descriptive or qualitative study and one of the articles was a well-designed quasi experimental study.

\begin{tabular}{ll}
\hline Author(year) & Major themes/findings/implications \\
\hline Akerjordet $^{5}$ & $\begin{array}{l}\text { Emotional intelligence was associated with positive empowerment processes, } \\
\text { prompting nurse leaders to continually reflect and evaluate, and improving their } \\
\text { supervisory and leadership capabilities } \\
\text { Critical reflection fosters the implementation of emotional intelligence in the context } \\
\text { of individual and surrounding differences }\end{array}$ \\
Akerjordet ${ }^{13}$ & $\begin{array}{l}\text { Emotional Intelligence provides a drive and passion to lead, accentuating their self- } \\
\text { awareness, self-regulation and social skills } \\
\text { Eason }\end{array}$ \\
Emotional Intelligence sharpens personal and social competence. It promotes effective \\
communication, cognitive decision making and professional empathy capabilities.
\end{tabular}


Table Continued....

\begin{tabular}{|c|c|c|}
\hline Author(year) & Major themes/findings/implications & Level of evidence \\
\hline Feather ${ }^{\prime \prime}$ & $\begin{array}{l}\text { Emotionally intelligent nurse leaders are required to combat the increasing turnover } \\
\text { and shortage of nurses }\end{array}$ & LevelV \\
\hline & $\begin{array}{l}\text { Staff working under emotionally intelligent leaders, reported increase tem work, job } \\
\text { satisfaction and improved quality of patient care }\end{array}$ & \\
\hline Foltin ${ }^{8}$ & $\begin{array}{l}\text { Strategies adopted by emotionally intelligent nurse leaders to implement a change } \\
\text { includes, explicit explanation to the team on what the change involves and to generate } \\
\text { enthusiasm and commitment from the team members }\end{array}$ & Level VII \\
\hline Heckemann ${ }^{15}$ & Emotional intelligence can be successfully implemented on a reflective framework & LevelV \\
\hline Horton-Deutsch ${ }^{14}$ & $\begin{array}{l}\text { The transition to clinical competence and leadership in practice requires self- } \\
\text { awareness and emotional intelligence. } \\
\text { Integrating theoretical learning with experiential learning promotes the development } \\
\text { of emotional intelligence }\end{array}$ & Level VII \\
\hline Hutchinson 9 & $\begin{array}{l}\text { Emotionally intelligent nurse leaders play a vital role in diminishing experiential bullying } \\
\text { in nursing }\end{array}$ & Level VI \\
\hline Lorber $^{12}$ & $\begin{array}{l}\text { From the employees point of view, emotionally intelligent nurse leaders are efficient in } \\
\text { managing change and conflict resolution }\end{array}$ & Level VI \\
\hline Lucas $^{16}$ & $\begin{array}{l}\text { Emotional intelligent becomes increasingly difficult to implement if span of control } \\
\text { increases }\end{array}$ & Level VI \\
\hline $\mathrm{O}^{\prime} \mathrm{Neill}^{10}$ & $\begin{array}{l}\text { Contemporary health care issues requires transformational leadership with emotional } \\
\text { intelligence }\end{array}$ & Level VII \\
\hline Wallis $^{7}$ & $\begin{array}{l}\text { Team dynamics requires Emotional Intelligence of key members holding supervisory } \\
\text { positions }\end{array}$ & Level III \\
\hline
\end{tabular}

One fourth of the studies reviewed had focused on the benefits of emotional intelligent leadership styles to nurses and the organization. Another quarter of the reviews showcased the necessity of emotional intelligence in the context of the current global healthcare scenario. Majority of these reviews outlined the strategic implementation of emotional intelligence in health care settings. Three studies outlined the significance of emotionally intelligent nurse leaders in specific health care setting, which were palliative care, oncology and mental health. One study broadcasted the lack of emotional intelligence in the nursing curriculum.

\section{Discussion}

Systematic review of empirical evidences on the practice of emotional intelligence by nurse leaders crystallized on the following themes.

i. Emotional intelligence is a charismatic virtue for Nurse Leaders.

ii. Emotional intelligence remediates the chronic challenges in nursing practice.

iii. The success of emotional intelligence is in its implementation

\section{Emotional intelligence is a charismatic virtue for} nurse leaders

Figure 1 Emotional intelligence carries with it a string of virtues which has strong significance among nursing leaders. Akerjordet ${ }^{5}$ reports that emotional intelligence is associated with positive empowerment a ability which is characterized by stronger selfawareness and supervisory skills. The combination of these virtues helps the nurse leaders to introspect the challenges and unsuccessful standards from their previous experiences and devise customized strategies to overcome the identified barriers. Cooper ${ }^{6}$ quoted that possession of emotional intelligence provides a drive and passion to lead. In this article his focus also includes self-regulation and social skills. These virtues contradicts the olden day styles of leadership, in which nurse leaders had the authority to enforce, extract and extinguish the abilities of their subordinates. When the virtue of self-regulation is activated subordinates are provided tasks which can be accomplished within the scope of their abilities, resources and time. Social skills is implemented by participative leadership, which eliminates the positional distance between the leader and the subordinate and provides room for clarification, opinions and innovations. Eason included the abilities of cognitive decision making and professional empathy to the characteristics of emotional intelligence. Emotional intelligence virtues has eradicated the stereotyped decision making efforts taken by nurse leaders based on policies and protocols. Decision making is a dynamic process among nurse leaders with emotional intelligence. It changes according to the cause, nature and consequences of the issue or challenge. The nurse leader employs her past knowledge and investigates current evidence based literature for solutions before deducing a decision. Empathy was never in the realm of leadership characteristics, however initiating this virtue in practice settings, eliminates the fear of control and facilitates freedom to express, explore and experiment. Nursing leaders with these virtues possess a charisma, which draws their subordinates towards them, which facilities effective and efficient delegation of tasks and also improves the organizational outcomes.

Nursing practice is based on the framework of teamwork. Wallis ${ }^{7}$ claims that team dynamics requires emotional intelligence of key members holding supervisory positions. Foltin ${ }^{8}$ supplements to the above discussion by stating that nurses who work under emotionally 
intelligent leaders reported greater teamwork, job satisfaction and increased quality of patient care. Emotionally intelligent leaders promote teamwork by their experiential understanding of a given task or situation. They are able to professionally emphasize with their subordinates and are not work extractors. The hierarchical difference among nursing fraternity often poses the novice nurses at risk for experienced bullying. Hutchinson ${ }^{9}$ recommends the need to strengthen nursing leadership capabilities associated with emotional intelligence to diminish experienced bullying within nursing. The author elaborates on the ways to accomplish this by stating that, a protocol or procedural response to bullying is to be developed in organizations. On an individual basis, the author recommends the need to respond to emotions and to support the intrapersonal and interpersonal capabilities of the nursing workforce. These strategies provides the space to voice out the bullying experience and also provides room for the leader to deal with such issues in the light of an individual's capacities. Contemporary health care and nursing practice issues, like escalating health care costs, transition in health care setting, conflict resolution and increased turnover requires the implementation of innovative nursing leadership expertise through transformational leadership and emotional intelligence. ${ }^{10-12}$ These authors have strategically stated that, emotionally intelligent leaders employ a more comprehensive cognitive approach in facing these challenges. Motivation and enhancing their subordinates understanding of the situation also pays a vital role in the resolution of these issues. ${ }^{8}$ Novice nurses are reared in carefully-controlled educational environments and are expected to practice in rapidly changing complex health care settings. Horton-Deutsch suggests that a transition to clinical competence and leadership in practice requires a strong sense of self and emotional intelligence. Leadership is an essential role-specific competency required in professional nurses, and novice nurses are perplexed at the expectation of this virtue at their hierarchical level. Providing to them the insight that self-awareness is the primary sign of leadership, enables them to confidently practice their educational experiences.

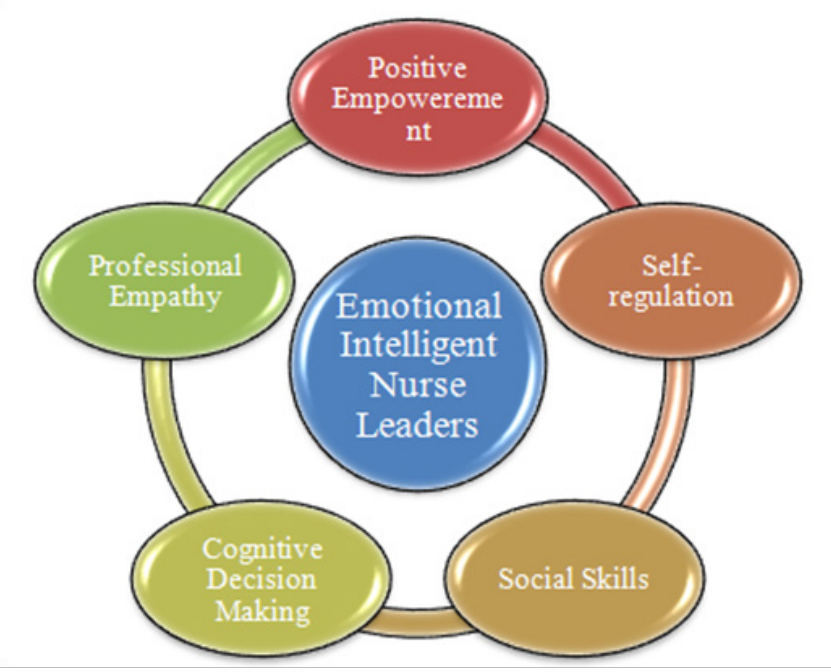

Figure I Emotional intelligence remediates the chronic challenges in nursing practice.

The success of emotional intelligence is in its implementation

Emotional intelligence is a virtue and not a responsibility which can be outlined on pen and paper. It is the cultivation of a nature which guides the doings, directions and decisions of nursing leaders. The implementation of emotional intelligence in practice settings cannot be generalized. It has to be considered in the context of the individual and surrounding differences. ${ }^{13}$ Hence a comprehensive assessment of the nature of the workforce, job requirements and outcomes of the organization has to be considered before regulating the varied composition in which emotional intelligence can be employed. Once incepted the proportion of these capacities have to be readjusted in accordance to the situation. Leaders who are to be nurtured with emotional intelligence should be reinforced to incorporate theoretical learning with their experiential learning. ${ }^{14} \mathrm{~A}$ constant recall of their cognitive and experiential backgrounds will facilitate professional empathy, which will provide them with a better understanding of the demands of a situation and the strategies they had employed in resolving it. This clearly implies to the need for progressively experiencing every phase of the job before holding leadership position. When employing emotional intelligence in a situation requiring change, the strategies implied in literature focuses on preparing the team by explicitly explaining the expected change; and initiating measures to generate their enthusiasm and commitment. ${ }^{8}$ This style of emotional intelligence sets off the pace within the team members to work with a passion and motive, yielding higher achievement of the outcome and satisfaction. Heckemann ${ }^{15}$ suggests implementing emotional intelligence through a reflective framework. Reflection requires introspection of onels emotions, thoughts or experiences in the context of its surroundings and evidence based practice standards, resulting in evolution of innovative and individualized remediation to challenges or concerns. Increasing the span of control can paralyze the positive effects of emotionally intelligent leaders. Hence it is essential to ensure that emotional intelligence is invested in an environment where the possibility of reduced span of control is permissible. ${ }^{16}$

\section{Conclusion}

Emotional intelligence is a dynamic ever evolving theme which requires a change in perception and a willingness to reflect and regulate constantly. Leaders who possess this capacity are rolemodelling this theme, which is the only way in which subordinates and team members are acquainted to this concept. As of now, the concept of emotional intelligent is absent in the nursing curriculum. A repackaging of the nursing curriculum with socialization processes is recommended by Hurley. ${ }^{17-19}$ From the context of nursing administration, recruiters should consider nurse managers with emotional intelligence. ${ }^{1}$ Research implications are directed towards ascertaining if emotionally intelligent leaders can improve the job satisfaction of their subordinates. ${ }^{11}$

\section{Acknowledgements}

None.

\section{Conflict of interest}

The author declares no conflict of interest.

\section{References}

1. Spano Szekely L, Griffin MT, Clavelle J, et al. Emotional intelligence and transformational leadership in nurse managers. J Nurs Adm. 2016;46(2):101-108

2. Rishel CJ. The role of resilience and mindful leadership in oncology nursing. Oncol Nurs. 2015;42(2):198-199. 
3. Powell KR, Mabry JL, Mixer SJ. Emotional Intelligence: A critical evaluation of the literature with implications for mental health nursing leadership. Issues Ment Health Nurs. 2015;36(5):346-356.

4. Davies S, Jenkins E, Mabbett G. Emotional intelligence: district nurses' lived experiences. Br J Community Nurs. 2010;15(3):141-146.

5. Akerjordet K, Severinsson E. Emotionally intelligent nurse leadership: a literature review study. J Nurs Manag. 2008;16(5):565-577.

6. Cooper J. Nurses as leaders-creating nurses with drive and passion. Aust Nurs Midwifery J. 2015;22(10):38.

7. Wallis A, Kennedy KI. Leadership training to improve nurse retention. $J$ Nurs Manag. 2013;21(4):624-632.

8. Foltin A, Keller R. Leading change with emotional intelligence. Nurs Manage. 2012;43(11):20-25.

9. Hutchinson M, Hurley J. Exploring leadership capability and emotional intelligence as moderators of workplace bullying. J Nurs Manag. 2013;21(3):553-562.

10. O’Neill JA. Advancing the nursing profession begins with leadership. $J$ Nurs Adm. 2013;43(4):179-181.

11. Feather R. Emotional intelligence in relation to nursing leadership: does it matter. J Nurs Manag. 2009;17(3):376-382.
12. Lorber M, Skela Savic B. Perceptions of managerial competencies, style, and characteristics among professionals in nursing. Croat Med J. 2011;52(2):198-204.

13. Akerjordet K, Severinsson E. The state of the science of emotional intelligence related to nursing leadership: an integrative review. J Nurs Manag. 2010;18(4):363-382.

14. Horton Deutsch SA, Sherwood G. Reflection: an educational strategy to develop emotionally-competent nurse leaders. J Nurs Manag. 2008;16(8):946-954.

15. Heckemann B, Schols JM, Halfens RJ. A reflective framework to foster emotionally intelligent leadership in nursing. $J$ Nurs Manag. 2015;23(6):744-753.

16. Lucas V, Spence Laschinger HK, Wong CA. The impact of emotional intelligent leadership on staff nurse empowerment: the moderating effect of span of control. J Nurs Manag. 2008;16(8):964-973.

17. Hurley J. The necessity, barriers and ways forward to meet user-based needs for emotionally intelligent nurses. J Psychiatr Ment Health Nurs. 2008;15(5):379-385.

18. Toni Eason DN. Emotional intelligence and nursing leadership: A successful combination. Creat Nurs. 2009;15(4):184-185.

19. Vitello Cicciu JM. Innovative leadership through emotional intelligence. Nurs Manage. 2003;34(10):28-32. 